\title{
Monitoring Key Points Analysis of Livestock Products Safety Regulation
}

\author{
Wang Keshan ${ }^{1}$, Wang Meng ${ }^{2}$, Liu Xiudong ${ }^{1}$ \\ ${ }^{1}$ Department of Economics, Beijing Wuzi University, Beijing, China \\ ${ }^{2}$ Department of Economics \& Management, China Agricultural University, Beijing, China
}

Email address:

Wksh6976@126.com (Wang Keshan)

\section{To cite this article:}

Wang Keshan, Wang Meng, Liu Xiudong. Monitoring Key Points Analysis of Livestock Products Safety Regulation. Science Journal of Business and Management. Vol. 5, No. 1, 2017, pp. 37-44. doi: 10.11648/j.sjbm.20170501.15

Received: December 12, 2016; Accepted: December 28, 2016; Published: March 2, 2017

\begin{abstract}
As the improvement of people's living standard, livestock products including meat, eggs, milk and other animal foods have become the main source of public nutrition intake, and the proportion in food consumption is more and more high. Livestock products consumption is regarded as one of important signs of a country's or region's economic development and the progress of society. As a kind of fresh products, livestock products have natural characteristics of putrescibility and not easy to save ( $\mathrm{Li}$ Yang, An Yufa, Gu Chuan 2013) [1], therefore it is prone to problems in the sectors of production, processing, transportation, storage, consumption. Besides, the quality problems of livestock products have been common such as "Water-injected meat", "quick chicken" and "magdala red" eggs and even some large food enterprises have serious quality problems of products. Therefore, ensuring food safety of livestock products should become the focus of the work of food safety and the research field of Chinese food safety. Wang Panpan (2010) defines the food supply chain for the order of link and operation from primary production to consumers, involving production, processing, distribution, storage and consumption of food and accessories. She thinks there are risk of food safety problems in the link of source, processing, distribution and consumption of food supply chain and should strengthen supervision on the key control points in above links [2]. M. F. Stringer (2007) divided the food supply chain into 27 unit steps and found out 21 essential reasons causing food safety problems, and based on which M. F. Stringer defined the key control points of food safety problems [3]. Bian Linlin (2010) studied game relation among supermarkets, suppliers, consumers and regulators with game theory and got the result that supermarkets play a role in promoting the establishment and development of China's food quality control system and supermarkets should strengthen the supervision and control on supplier and internal staff [4]. Through the researches of agricultural leading enterprises in Hunan Province, combined with the principle of the HACCP, Xie Jingwen (2012) proposed that we should position the key points of supply chain, which is helpful to the whole process monitoring of food supply chain and the establishment of the traceability system for monitoring food [5]. Liu Chang (2012) constructed the food quality and safety SC-RC discriminant and location matrix based on 1460 food safety cases, and analysed the weak links and key control points of food safety in our country with empirical analysis [6]. In summary, domestic and foreign scholars have been carried out on the key control points of food safety and made a lot of research results. But most studies take all food as research object, but location of different food the key control points should also be different and this study intends to analyze the livestock products.
\end{abstract}

Keywords: Livestock Products, Safety Regulation, Key Points

\section{Data, Models and Research Methods}

\subsection{Data}

The data of empirical study is from the livestock products safety incidents exposure in the internet. The period is from 2001 to 2013, a total of 278 onwards. (as shown in Table 1) 
Table 1. Livestock products safety incidents statistics from 2001 to 2013.

\begin{tabular}{ll}
\hline Year & Event Capacity \\
\hline 2001 & 1 \\
2002 & 1 \\
2003 & 5 \\
2004 & 2 \\
2005 & 27 \\
2006 & 28 \\
2007 & 25 \\
2008 & 27 \\
2009 & 34 \\
2010 & 11 \\
2011 & 68 \\
2012 & 33 \\
2013 & 16 \\
total & 278 \\
\hline
\end{tabular}

\subsection{Models}

Livestock products safety issues are likely to occur in every sectors of supply chain and the essential reasons are varied. If we can put the supply chain and the essential reason as two dimensions analyzing the case, the key point of livestock products safety issues can be positioned. Based on this idea, the paper constructed livestock products quality and safety SC-RC discriminant and location matrix through drawing lessons from the domestic and foreign research theory.

The first dimension of matrix is livestock products supply chain (SC). According to the stages of food production, processing, circulation and consumption, we divide the supply chain into 7 parts (as shown in Table 2).

Table 2. Livestock products supply chain

\begin{tabular}{ll}
\hline Link & Illustration \\
\hline Production (A1) & Breeding and slaughter of livestock products \\
wholesale (A2) & Wholesale of livestock products \\
machining (A3) & Processing of livestock products, including initial processing and deep processing \\
transportation (A4) & Transport links of livestock products, including raw materials and processed products \\
Storage (A5) & Storage of livestock products, including raw materials and processed products \\
retail (A6) & Livestock products retail links, including raw materials and processing will be the product \\
Dining and dining hall (A7) & Household or food and beverage premises for the cooking of livestock products or direct consumption of links \\
\hline
\end{tabular}

The second dimension of matrix is essential reason of livestock products quality problems the paper summarizes 12 nature factors causing livestock products quality problems (as shown in Table 3).

Table 3. The essential reason for livestock products quality safety.

\begin{tabular}{ll}
\hline Essential Reason & Illustration \\
\hline Improper use of natural raw materials (a1) & Use of natural raw materials or other alternative materials \\
Use of recycling waste (a2) & Use of waste as raw material production, processing \\
Using substandard materials (a3) & Using poor quality raw materials \\
Add harmful inputs (a4) & Use of prohibited additives or other harmful chemical raw materials \\
Improper processing procedure (a5) & Not processed in accordance with the prescribed procedures \\
Improper use of elements (a6) & Inadequate or excessive use of elements \\
Improper storage of raw materials (a7) & Raw material storage environment is not up to standards caused by micro-organisms \\
Improper packing (a8) & Not required to carry out packaging or product label fraud \\
Personnel environment is not health (a9) & Personnel, environmental health is not up to \\
Improper disposal of waste (a10) & Fails to recycle waste, resulting in its re entering the circulation \\
Improper storage of finished products (a11) & Product storage conditions are not up to standard \\
Natural environment pollution (a12) & Food safety incidents caused by the natural environment \\
\hline
\end{tabular}

\subsection{Research Methods}

The paper use livestock products SC-RC discriminant and location matrix to do the empirical research. SC-RC discriminant and location matrix means that regard supply chain and the essential reasons of food safety incidents as two dimensions of problem analysis, investigate the supply chain and essential reasons of one specific food safety incident, count the number of food safety incidents caused by some supply chain for some reason, and then position the key point of livestock products safety issues accurately.

This study takes livestock products in China as the research object, collect livestock products safety events from 2001 to
2013 exposured by the network which number is 300 . After removing the fake, 278 effective cases are left. The cases collected occurred across the country, not existing biased recording on some area, On the other hand, from the incident link, not existing focus on some link too. Therefore, the data selected in this study is objective and effective, which can reflect the characteristics of livestock products safety incidents in our country actually. By analyzing initial link and the essential reason of food safety accidents, we can position the key points of risk prevention and control of livestock products in China, and find the weak link further, provide a reference opinion for the supervision department about supervision in advance on food safety events. 


\section{Statistics and Analysis of Livestock Products Safety Incidents}

\subsection{Frequency Analysis of Animal Food Product Safety Incident}

Food safety incidents are likely to occur in every sector of supply chain. After dividing food supply chain into segments, we position food safety incidents correspondingly and count and analyze food safety incidents. The frequency of food safety incidents in every sector is as shown in Figure 1.

From the point view of supply chain, the number of livestock products safety incidents in the process of machining is the most, far higher than other sectors, followed by is the production link. Besides, the problem is also outstanding in the process of Wholesale and retail links. The processing link is a process of product value added. Based on the hypothesis of "rational man" livestock products processing enterprises take economic benefits as the first guide. Compared with developed countries, livestock products processing enterprises in China have low threshold. Except the deep processing link which asks for technical level and equipment level, Initial processing link which asks for simple operation and technical content are generally managed by smaller individuals or companies. Products in initial processing link will be raw material in the deep processing link, but because of existence of serious information asymmetry, deep processing enterprises is hard to accurately grasp product quality in Initial processing link. If Initial processing enterprises manage enterprises illegally, products produced by livestock products enterprises engaged in deep processing will also have quality and safety problems. Faced with the small and medium scale livestock food processing enterprises which is large number and in different levels, supervision and law enforcement is relatively weak, which is the key reason for frequency of livestock food safety events in processing sectors.

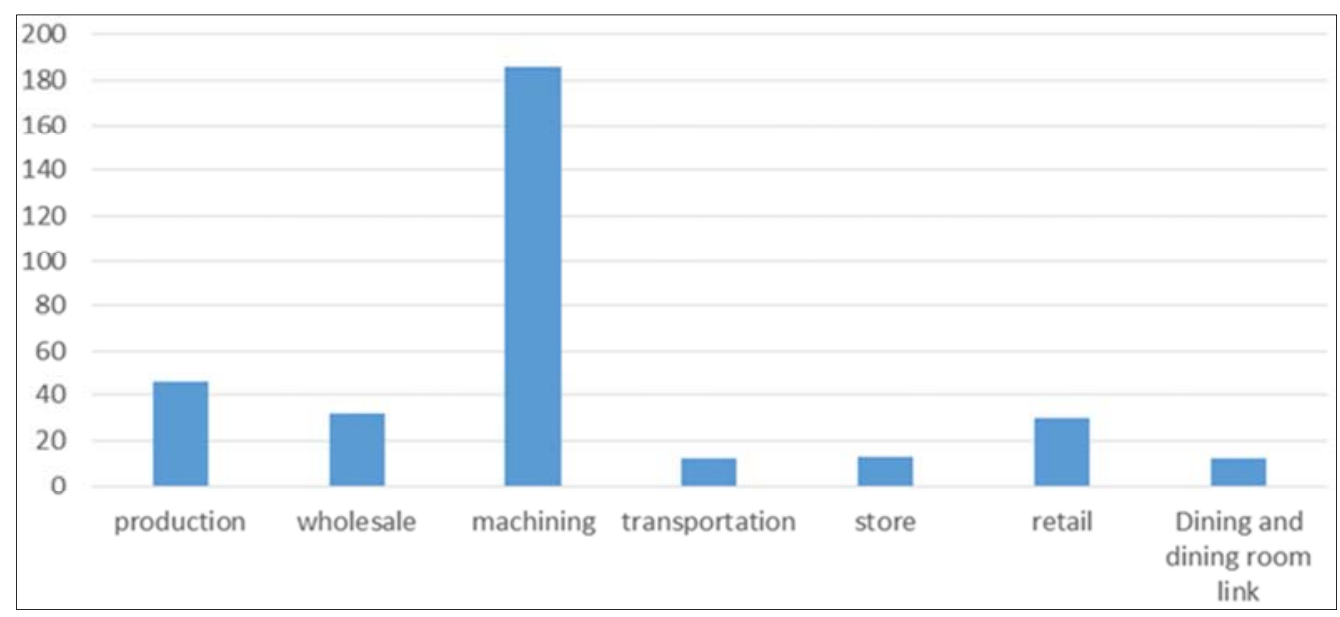

Figure 1. Analysis of occurrence frequency of livestock food safety incident in every link.

\subsection{Analysis on the Essential Cause of Safety of Livestock Products}

According to the characteristics of livestock food, we summed up 12 essential reasons for livestock products safety incidents. the results of statistics and analysis on the essential reasons for these livestock products safety incidents are shown in Figure 2.

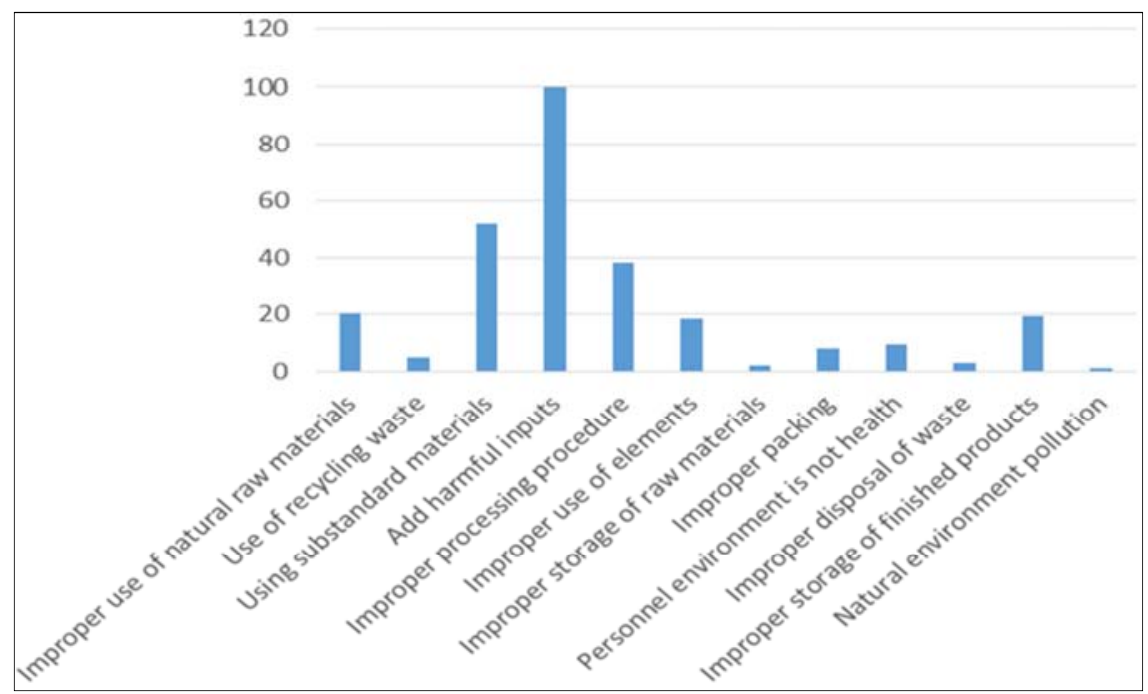

Figure 2. The analysis of essential reasons for livestock food safety incidents. 
From the aspect of the essential reason, the problem of adding harmful inputs is the most prominent, followed by the use of substandard materials, food safety incidents caused by improper processing procedures, improper use of natural raw materials, improper environment of finished products storage, improper use of elements are also a lot of quantity. Livestock products processing enterprises adding harmful inputs are usually small workshops and their processing quality is poor, their quantity is huge and their law-abiding consciousness is weak. More importantly these illegal behaviors have feature of concealment, therefore the relevant departments have relatively weak supervision on adding harmful inputs and law enforcement is relatively passive. Some of processing enterprises using substandard raw materials are cheated by upstream raw material suppliers, some are forwardly collude with upstream raw material suppliers. What is more, some law enforcement departments in some areas take the initiative to participate in the operation of this black chain instead of supervising although they know someone is doing something illegal.

\section{Analysis on Key Points of Livestock Food Safety Risk Monitoring}

We got the result showed in Table 4 by using food quality and safety SC-RC discriminant and location matrix.

The supply chain, the essential reason and occurrence frequency of livestock products safety incidents are indicated by "supply chain-Essence-frequency" in this study. For example,"A3-a4-78" means that the frequency of occurrence of livestock food safety incidents caused by adding harmful inputs in processing is 78 . The total frequency is 325 . If the frequency is more than the total number of cases, it is because some events reflect various essential reasons in various links.

Table 4. Food quality and safety SC-RC discriminant and location matrix.

\begin{tabular}{lllllllll}
\hline $\mathbf{R C}$ & $\mathbf{A 1}$ & $\mathbf{A 2}$ & $\mathbf{A 3}$ & $\mathbf{A 4}$ & $\mathbf{A 5}$ & $\mathbf{A 6}$ & $\mathbf{A 7}$ & total \\
\hline a1 & 1 & - & 8 & - & - & 3 & - & 12 \\
a2 & - & 2 & 6 & - & - & 1 & - & 9 \\
a3 & 16 & 10 & 31 & 2 & 1 & 6 & 1 & 67 \\
a4 & 21 & 8 & 78 & 1 & - & 5 & - & 113 \\
a5 & - & 1 & 32 & 2 & 3 & - & 5 & 43 \\
a6 & 5 & - & 12 & - & - & - & 1 & 18 \\
a7 & - & 6 & 2 & - & 1 & - & 2 & 11 \\
a8 & - & - & 6 & 1 & - & 2 & - & 9 \\
a9 & - & - & 5 & - & - & 2 & 2 & 9 \\
a10 & - & 6 & 1 & - & 1 & 4 & - & 12 \\
a11 & - & - & 5 & 4 & 6 & 6 & - & 21 \\
a12 & 1 & - & - & - & - & - & - & 1 \\
total & 44 & 33 & 186 & 10 & 12 & 29 & 11 & 325 \\
\hline
\end{tabular}

\subsection{Supply Chain Location}

\subsubsection{Livestock Products Processing Sectors}

Number of livestock products safety incidents in processing sectors are most, a total of 186 , accounting for $57.2 \%$. According to the fourth chapter and twenty-ninth provisions in
《Law of the People's Republic of China on Food Hygiene》, food producers obtaining food production license selling food they produce in their production premises need not obtain a food circulation permit; catering service providers obtaining catering service license selling its production in their food service establishments are not required to obtain food production and circulation license; individual farmers selling self-produced edible agricultural products, do not need to obtain a food circulation permit. Therefore access to food processing industry is easy in China which contributes to a lot of Individual or enterprises having weak legal consciousness and not having food processing qualification enter the field. In addition, there exist opportunistic psychology in enterprises and when the profit by making and selling fake products is far higher than the penalties and losses supervision departments punish, some food processing enterprises will machining improperly products.

Numerous processing steps and supervision departments needing to control raw material selection, processing, packaging, personnel practices, environmental health and other sectors also objectively led to Regulatory difficulties in law enforcement. In the cases collected, we found after the changes "bad money drives out good money" in " lemon market ", some food processing enterprises in large scale put harmful material to health at the expense of the corporate image, causing a bad influence and great consequences. Therefore, the work of monitoring the food processing sectors should be the focus to supervision departments, and enterprises should also bear the social responsibility instead of ignoring legal and credit in order to chase economic interests.

\subsubsection{Livestock Products Production}

Production link is also a serious sector in livestock products safety incidents. The problem mainly reflected that farmers or farming sector use feed containing additives, illegal veterinary drugs and toxic agent crash and problematic vaccine in the process of production and breeding.

Compared to European countries, livestock husbandry in China have characteristics of too many departments of organization and low degree of industrialization and organization. Faced with the large number and uneven level farming sector, how to supervise effectively is a big problem, which is an important reason for frequent production problems in production link. In addition, some departments do not pay attention to the feces, garbage and waste produced in the treatment In the process of livestock and poultry breeding, which will lead to serious pollution of the surrounding environment directly to the health of human and livestock. According to Liu Li Yao (2011), a chicken farms with 10000 chicken produce 360 tons chicken manure annually; a cattle farm with 100 cattle produce 680 tons cattle manure annually; a hogpen with 1000 pigs produce more than 2000 tons pig manure annually [7].

\subsubsection{Livestock Products Wholesale Link}

Wholesale Link is an important part of livestock products circulation, 4300 existing domestic agricultural products 
wholesale market bear more than $70 \%$ circulation of agricultural products wholesale markets [8]. Compared to other circulation places, wholesale markets have characteristics of trading volume and stable customers [9]. If food problem emerges in this part, it will cause harm to a wider range of consumers. Among empirical research cases in this study, the number of food safety incidents occurring in this link is 33 , accounting for $10.2 \%$ of the total incidents. Problems are mainly reflected in: businesses selling products not quarantine and unknown sources; Some merchants inject water for pigs or cows openly in order to seek private interests; Some wholesaler provide recycling dead rotten pork for commercial tenant.

\subsubsection{Livestock Products Retail Link}

The number of empirical research cases occurring in the retail link in this study is 29 , accounting for $9 \%$ in all cases, the same with wholesale segment basically. The retail sector is the last circulation of livestock products before reaching hands of consumers, and also the last dispatched point of circulation system controlling quality safety [10]. Problems mainly reflects in the following aspects: retailers selling counterfeit and substandard commodities; substandard goods packaging standards or labels are not clear; supermarkets sell expired, spoiled meat or milk drinks; supermarket staff do not pay attention to the maintenance of fresh carnivorous environment In the cases collected, some large scale retailers have frequent problems in this part. For example the WAL-MART chain supermarket has repeatedly exposed that selling overnight processing of meat to consumers. Although there are less accidents occurring in this link, but regulators cannot treat it lightly.

\subsection{Nature Reasons}

\subsubsection{Add Harmful Inputs}

The number of livestock products safety issues caused by addition of harmful inputs are 113 , accounting for $34.8 \%$ in overall proportion, that is to say, more than $1 / 3$ cases collected are due to processing personnel adding harmful additives and leading to food safety incidents. The type of prohibited substances in food is various and reasons are different. For example, some processors handle cow board with Industrial formaldehyde and hydrogen peroxide in order to boil the rotten and looks pale and bright; some processors handle pork with borax and rouge in order to make the color of pork look red; some processors handle chicken and duck with asphalt in order to pick hair easily; some processors adding melamine into the milk to increase the amount of nitrogen test (SanLu melamine incident); in the process of breeding, some processors feed pigs feed containing "lean meat powder" to produce "lean-meat pig" (Shuanghui "lean meat powder" incident). Reasons for these small food processing workshops and enterprises in adding harmful chemical substances to the product are various, but what's the important is that supervision of the regulatory authorities are not in place. punishment for the criminal acts is not large enough so that these enterprises select the act of wrongful acts after comparing the marginal cost and marginal revenue [11].

\subsubsection{The Use of Substandard Raw Materials}

The number of food safety incidents cases caused by the use of substandard raw materials accounts for $20.6 \%$ of the total number cases. Cases of food safety problems caused by this reason occurred in many aspects of the supply chain. In the process of production, some farmers inject water to cattle, pigs and other livestock; in the wholesale segment, wholesalers sold meat, poultry and eggs without quarantine to downstream businesses; in the process of production, some food processing enterprises deceive consumers with poor quality raw materials instead of good quality raw materials; In the retail link, supermarket or individual household sell the meat and milk unknown source. In fact, some cases reflect the shocking truth. Because of the absence of regulation in some areas, it has formed the black industry chain which unqualified raw materials trade and circulate. Some sick pigs and dead pig are not handled according to requirements, instead, they come into the circulation once again. From the production, wholesale, processing to retail sectors, each participant in this chain know the source and quality of raw materials clearly, while the consumer has become the ultimate buyers and victims in the black chain.

\subsubsection{Improper Processing Procedure}

Numbers of food safety incidents cases caused by improper procedures accounting for $13.2 \%$ in the total cases. After the review of cases, those not operating according to the rules are mainly large-scale businesses and certain dining establishments. The reason is that small-scale food processing enterprises can not participate in deep processing which requires high technology and equipment level because of the limitation of technology and equipment while and livestock products initial processing, therefore, the problems in the small-scale food processing enterprises have no chance objectively. Enterprises having much problems are most milk products business. in the process of high temperature sterilization of dairy products, some milk products business invest not enough in this part, resulting in bacterial in some products exceed the standard and even becoming the expired products within the warranty period; in the packaging process, some operators are negligent, resulting in products mixing other things. Products have not been carefully checked before entering the markets, leading to products with serious quality problems enter the market; Food processing procedures improper performance in the meat cooking time is not enough, leading to consumer diarrhea; not removing the poisonous parts of raw materials leading to consumer food poisoning.

\subsection{Positioning of Critical Control Points for Safety of Livestock Products}

Through the analysis of supply chain and the essential reason, we can position 5 critical control point of high food safety incidents frequency in the SC-RC discriminant and location matrix, according to the frequency, arrangement is: hazardous materials input in processing link (A3-a4-78), 
improper processing in processing link (A3-a5-32); use of unqualified raw material in processing link (A3-a3-31); hazardous materials input in producing link (A1-a4-21); use of unqualified raw material in producing link (A1-a3-16).

\subsubsection{Analysis of Hazardous Materials Input in Processing Link}

Number of food safety incidents caused by hazardous materials input in processing link is 78 , accounting for $42 \%$ of total incidents in the processing link. These harmful inputs are most chemical substances which are toxic to human. These illegal processing enterprises and private business have characteristics of large scale and concealment, objectively increased the supervision difficulty of law enforcement departments.

\subsubsection{Analysis of Improper Processing in Processing Link}

Number of food safety incidents caused by improper processing in processing link is 32 , accounting for $17.2 \%$ of total incidents in the processing link. Enterprises occurring food safety accidents because of improper processing are most milk products business in this link. Processing characteristic of milk products business is much process and it is hard for supervision departments to supervise comprehensively. As a result, it leaves a space for milk product enterprises to hole loopholes. Holing loopholes mainly reflecting: Milk product enterprises purchase raw milk unknown origin as raw material in producing link; Measures of sterilization are not enough in processing link; Label is unclear and ambiguous information in packaging link.

\subsubsection{Analysis of Unqualified Raw Material Use in Processing Link}

Number of food safety incidents caused by unqualified raw material use in processing link is 31 , accounting for $16.7 \%$ of total incidents in the processing link. It is hard for processors to judge the raw materials quality supplied by superior supplier because of the information asymmetry so that processors use substandard raw materials for processing accidentally, while some processors and supplier act evilly in collusion with each other and buy and sell substandard raw materials for production openly. It emphasizes the establishment of livestock products traceability mechanism and management of the relevant departments for livestock food source.

\subsubsection{Analysis of Hazardous Materials Input in Producing Link}

Hazardous materials input in producing link is the most prominent problem. Number of food safety incidents caused by hazardous materials input in producing link is 21 , accounting for $47.7 \%$ of total incidents in the producing link. In order to seek personal gain, farmers feed cattle feed containing carcinogenic substances and hormones in producing link. Because industrialization of aquaculture in China is in low level, farmers are small-scale but large number, regulators can't and purchase of downstream processors are unstable and can't effectively control upstream farmers, which makes the source problem is prominent.

\subsubsection{Analysis of Use of Unqualified Raw Material in Producing Link}

Number of food safety incidents caused by use of unqualified raw material in producing link is 16 , accounting for $36.4 \%$ of total incidents in the producing link. The problem is reflected in three aspects: the one aspect is that the producers inject water to pork, beef and weight of meat injected water will increase, which is fraud. What is more, criminals inject water to pork and beef with sewage, brine and alum water, which have a great threat to the health of consumers and brine and alum water are likely to lead to cancer; the two aspect is the producers sold sick and dead livestock to downstream secretly instead of handling them according to the provisions; the three aspect producers act evilly in collusion with law enforcement and cover official seal for livestock without quarantine to make them enter the circulation. Producing is the source of the supply chain. If we emphasize source management for food safety, we need to focus on the management of upstream farmers and aquaculture enterprise.

\section{Conclusion Analysis and Suggestion}

\subsection{Conclusion Analysis}

Based on the empirical analysis on 278 livestock products quality and safety incidents by using SC-RC discriminant and location matrix, this study positions 5 critical control points of livestock products safety risk monitoring in China.

From the perspective of the food supply chain, regulatory supervision department should supervise processing link and producing link intensively. Producing link is the initial link of the food supply chain, if ignore the source of food supply chain management, even if the other participants business legitimately, safety of livestock products can't guarantee. But livestock food producers in our country have characteristics of small scale, large number and thin Foundation and only relying on the government's administrative measures to supervise is not realistic, therefore, we need to take the way of administrative measures and market regulation to supervise. The government can strengthen the supervision on raw materials safety of downstream processing enterprises and increase penalties on the illegal business of processing enterprises to make the cost of processing enterprises is more than the profits using inferior raw material production and encourage livestock food processing enterprises to use normal livestock raw material provided by livestock food producing enterprises.

From the perspective of essential reasons for livestock products safety problems, regulators should focus on the supervision on the problems of substandard materials use, hazardous materials input, improper processing procedure. At present, food safety technical regulation and standard establishment delay in China, especially the safety standards and testing methods standard are prominent. The problems reflected in food standards system is chaotic because different 
regulatory authorities have different standard management and management. Even standard of same product in different industry have serious conflicts and detection method standards and comprehensive quality control system are lack. Therefore enterprises for processing production will be unable to fit in the situation and the government will be in a lawless situation in the supervision.

Through empirical analysis of livestock products safety incidents, we can find enterprises with illegal operation in the processing are usually poor quality, smaller enterprises, indicating that the livestock products processing industry in China to enter the threshold is low, which is concealed for illegal operations and processing enterprises. Faced to the large number products processing enterprises with poor legal awareness, the government should intensify law enforcement efforts to ensure livestock products safety.

\subsection{Suggestions}

\subsubsection{Strengthen the Source of Livestock Food Management}

Establish effective livestock food traceability system, improve the level of industrialization of farming practitioners, encourage farming households form professional cooperatives and improve the degree of organization. Guide farmers breeding scientifically. Increase quarantine efforts of livestock products to prevent food safety problems from the source. Encourage conditional large livestock products processing enterprises to establish breeding base by themselves. Take the way of normative and harmless green farming for breeding; For the processing enterprises not having condition establishing breeding base by themselves, it can be taken into account that sign the contract with formal farming enterprises, clear responsibility and ensure the safety of raw material in the form of contract.

\subsubsection{Strengthen the Supervision of the Processing Link of Livestock Products}

Livestock products safety problems occurred most in the processing link and therefore government should focus on monitoring this link, hazardous materials input, improper processing and the use of substandard raw materials are important cause of food safety issues. Based on this fact, we should strengthen supervision on the key process in the processing, such as element inputs, the use of raw materials, additives and so on. Strengthen the whereabouts management of food additives strictly, require the livestock products processing enterprises should put on record to relevant departments when purchasing food additives and examine enterprise products occasionally. Establish integrity platform of food processing enterprises. Once enterprise products have problems, exposure it's illegal activities to improved the cost of illegal processing enterprises greatly. Compared with western countries, food quality standards in China are lower, and some additive safety is unknown, therefore our country should be in line with international standards to improve quality standards.

\subsubsection{Standard Livestock Products Retail Market}

The retail link is a key link livestock products meet consumers directly, but also a link food safety incidents occurred frequently. Supervision departments should strengthen the supervision on this link. Livestock products retail market in China are composed of supermarkets, farmers markets and other components. Different market manages the products differently, which poses a great challenge for product testing; on the other hand, operators like farmers market and morning markets have strong liquidity, therefore once products have problems, it is difficult to investigate responsibility. The government should strengthen the construction of the retail market, maintain the retail market environment, raise the threshold entering the market. The retail market should also coordinate with work of inspection departments and industry and commerce departments actively and strengthen management on their business and product at the same time.

\subsubsection{Strengthen the Construction of Livestock Food Wholesale Market}

The wholesale market is an important juncture of food safety supervision in the circulation area which has very important significance to ensure food safety and quality safety of the whole process from farm to table. It is necessary to strengthen the construction of wholesale market infrastructure and supporting facilities docking modern circulation industry, establish and improve agricultural product quality safety inspection agencies and regulatory system, check access to agricultural products market strictly. At the same time, attach importance to improve the organization and scale degree of market traders in the market, cultivate and develop large wholesalers, large agents and large distribution providers.

\section{Acknowledgements}

The paper are funded by Beijing Social Science Fund Project "Study on the innovation of food quality and safety management policy in Beijing" (15JGB106).

\section{References}

[1] Li Yang, an Yufa, Gu Chuan. China fresh agricultural products food safety incident analysis and critical control point positioning [J]. Agricultural Economics and Management, 2013 (5): 31-35.

[2] Wang Panpan. The relationship between food supply chain and food safety [J]. Meat Food research, 2010 (1): 59-64.

[3] M. F. Stringer, M. N. Hall, The Breakdowns in Food Safety Group. A generic model of the integrated food supply chain to aid the investigation of food safety breakdowns $[\mathrm{J}]$. Food Control, 2007, 18 (7): 755-765

[4] Bian Linlin. The role of supermarket in the guarantee of food safety -- Game Analysis on the interest topics in the supermarket food quality control system [J]. Jiangsu Business Theory, 2010 (5): 5-6. 
[5] Xie Jingwen. Food safety and quality control based on HACCP system--An Empirical Study from leading enterprises in Hunan province [J]. JiLin Agriculture, 2012 (9): 243-245

[6] Liu Chang, Zhang Hao, An Yufa. Studies on the Weak Links, Essential Causes and Critical Control Points of Food Safety in China $\neg--$ An Empirical Analysis Based on 1460 Food Safety Events [J]. Agricultural Economics, 2011 (1): 24-31.

[7] Liu Liyao, Yuan Lin. Research on the development strategy of healthy aquaculture in the perspective of food safety [J]. «HeiLongJiang animal husbandry and Veterinary Medicine» comprehensive guide, 2012 (3): 15-17.

[8] Zhang Dan, Ge Chuan. Thinking about the construction of modern agricultural products wholesale market in China $[\mathrm{J}]$. science and technology information development and economy, 2007 (8): 90-91.

[9] Ren Yan, an Yufa. [J]. consumption economic factors on consumer confidence in the safety of food and its effects, 2009 (2): $45-48$.

[10] Wang Qiang, Gao Chunxian. Edible agricultural products quality and safety issues and process control [J]. Zhejiang Journal of Agricultural Sciences, 2004 (5): 247-253.

[11] He Pinghua, Ling Yuanyun, Liu Huanan. Analysis of consumer use of food signal and its influencing factors -- from 9 City, county consumer survey [J]. China rural survey, 2008 (4): 41-52. 